Article

\title{
Integrating Recovery within a Resilience Framework: Empirical Insights and Policy Implications from Regional Australia
}

\author{
Lex Drennan, Jim McGowan and Anne Tiernan* \\ Policy Innovation Hub, Griffith University, South Brisbane, 4101, Australia; E-Mails: I.drennan@griffith.edu.au (L.D.), \\ james.mcgowan@griffith.edu.au (J.M.), a.tiernan@griffith.edu.au (A.T.) \\ * Corresponding author
}

Submitted: 31 August 2016 | Accepted: 23 October 2016 | Published: 28 December 2016

\begin{abstract}
Within Australia's federal system, responsibility for preventing, preparing for, responding to and recovering from natural disasters is shared between the three tiers of government. Intergovernmental policy and funding arrangements are premised on shared responsibility and aim to foster individual, business and community resilience. These arrangements underpin Australia's international reputation for effectiveness in its management of natural disasters. The capacity of the diverse networks that comprise the disaster management system to coordinate and deliver in the preparedness and response phases of a disaster, and to provide relief in the immediate aftermath, has been developed over time and tested and refined through the experience of frequent, severe disaster events over recent decades. Less well developed is the system's ability to support economic recovery in disaster-affected communities over the longer term. This paper presents case studies of regional communities affected by two of Australia's most expensive and deadly natural disasters-the 2009 Victorian bushfires and the cyclones and floods that struck the state of Queensland in 2010-2011. It highlights significant gaps in policy and funding arrangements to support recovery and offers lessons for aligning recovery within a resilience framework.
\end{abstract}

\section{Keywords}

disaster governance; disaster recovery; economic recovery; resilience policy

\section{Issue}

This article is part of the issue "Disaster Policies and Governance: Promoting Community Resilience", edited by Naim Kapucu (University of Central Florida, USA) and Abdul-Akeem Sadiq (Indiana University-Purdue University Indianapolis, USA).

(C) 2016 by the authors; licensee Cogitatio (Lisbon, Portugal). This article is licensed under a Creative Commons Attribution 4.0 International License (CC BY).

\section{Introduction}

Natural disasters are inherent to Australia's climate, geography and environment. Disaster events span the spectrum of hazards from bushfire, cyclone and earthquake to flood, heatwave and storm surge. Since 2009, natural disasters have wrought damage and destruction to life, infrastructure, private property and the natural environment across the states and territories. The estimated total economic costs of natural disasters was calculated to have been AUD\$9 billion (USD\$6.9 billion) in 2015. ${ }^{1}$ Some reports predict this may increase to as much as
AUD\$33 billion (USD $\$ 25.5$ billion) per year by 2050 as the impacts of climate change increase (Deloitte Access Economics, 2016, p. 2). Australia follows the comprehensive approach to disaster management, which comprises the phases of prevention ${ }^{2}$, preparation, response and recovery (the PPRR framework) and addresses all hazards. Within Australia's federal system, responsibility for preventing, preparing for, responding to and recovering from natural disasters is shared between the three tiers of government. Intergovernmental policy and funding arrangements are premised on shared responsibility and, since 2001, have aimed to foster individual,

\footnotetext{
${ }^{1}$ Currency conversions to USD are calculated at the prevailing exchange rate for the period in question.

2 By 'prevention' we mean 'mitigation' as it is the more common technical term used around the world.
} 
business and community resilience. Less well developed, however, is the system's ability to support economic recovery in disaster-affected communities and to embed resilience over the longer term (see, for example, McGowan, 2014; McGowan \& Tiernan, 2014).

This article responds to calls for more holistic approaches to disasters and in particular, economic recovery. It draws on the findings of a major study of the experiences of economic recovery practices in regional communities affected by two of Australia's most expensive and deadly natural disasters - the 2009 Victorian bushfires and the cyclones and floods that struck the state of Queensland in 2010-2011 (Regional Australia Institute [RAI], 2013). Our case studies highlight significant gaps in policy and funding arrangements to support recovery. We identified a disconnect between the experience and lessons learned from disaster recovery and prevention and preparedness. Indeed, we found that actions and decisions of policy-makers taken in the immediate aftermath of a disaster had the unintended consequence of undermining individual and community resilience over the longer term.

Since resilience remains the core policy intent, we offer lessons for how Australia's disaster governance arrangements, and those of other countries, might be amended to embrace 'adaptive resiliency' - 'the ability to adapt through the redevelopment of the community in ways that reflect the community's values and goals, and its evolving understanding of the external forces with which it must contend' (Kapucu, Hawkins, \& Rivera, 2013, p. 357). We conclude that the 'structural' or 'engineering approach' to resilience has become predominant in Australia's disaster governance, leading to a primary focus on reconstruction during the recovery phase postdisaster. Our case studies demonstrate the imperative for a greater focus on 'non structural' resilience, in particular the 'community capital' that can be brought to bear, to develop adaptive capacity and adaptive resilience.

In the context of this thematic issue, which is focused on promoting community resilience through disaster policies and governance, this article offers empirical support for the 'adaptive resiliency framework' proposed by Kapucu et al. (2013, p. 356). A key element of their framework is 'integrating learning and adaptation into the traditional phases of disaster management'.

\section{Disaster Recovery: An Overview of Policy Issues in Australian Arrangements}

Government funded disaster relief in Australia operates within the framework of the Natural Disaster Relief and Recovery Arrangements (NDRRA) (Attorney-Generals Department, 2012). The NDRRA framework establishes cost sharing arrangements between the State and Federal Governments as well as specifying eligible expenditure activities. Since 2007 the NDRRA has included provision to redevelop eligible public infrastructure to a higher, more resilient standard. Known as the principle of 'bet- terment', this provision provided-at least in theorythe link between recovery and mitigation against future disasters (McGowan, 2014). Its adoption was intended to align with the goal of improving community resilience, formalized in the National Strategy for Disaster Resilience 2011 (NSDR).

Despite numerous disasters requiring reconstruction and spiralling expenditures under NDRRA (see Productivity Commission, 2014), only limited use has been made of the betterment provision. Until 2012 when the Queensland Government instituted a AUD\$40 million (USD\$40.9 million) fund that was matched by the Federal Government, the only successful application had been for a community pool betterment program in regional NSW (Productivity Commission, 2014). This remains an area of significant policy contention between the Commonwealth and State governments. Extraordinary increases in NDRRA expenditure-approximately AUD\$12 billion (USD\$10.7 million) from 2009-2013 can be contrasted with investments in mitigation under the Natural Disaster Resilience Program (NDRP) that totalled AUD\$100 million (USD\$89 million) over the same period (McGowan \& Tiernan, 2014, p. 8).

In 2013 then Commonwealth Treasurer, Joe Hockey, tasked the Productivity Commission with responsibility for conducting a comprehensive review, including of costsharing principles and the apparent 'weighting' of Commonwealth funding towards recovery. The Commission was asked to 'take into account the priority of effective mitigation to reduce the impact of disasters on communities' (Productivity Commission, 2014, p. iv). At the time of writing, the Commonwealth government has acknowledged receipt of the report, but has not made a formal policy response to its recommendations.

Whilst these challenges, and the original impetus for the research project, arose in the context of Australian disaster management policy, they are not unique to Australia. A series of reports has identified the growing costs of disaster recovery and reconstruction around the world, all calling for an increased emphasis on building resilience to minimise the costs, both human and financial, of disasters and subsequent recovery. The research presented in this paper was conducted within the context of disaster resilience frameworks that are broadly applicable to all communities, with one important caveat that has implications for generalizability. That is, that it was conducted in Australia-a broadly stable, advanced democracy characterized by sound principles of governance and accountability. Thus, questions of state stability are not considered in our discussion of resilient communities.

\section{Literature Review}

\subsection{Resilience Frameworks}

In recent years, the concept of resilience has gained currency in disaster management policy. Originating in 
ecology and psychology, resilience is envisaged by some scholars as both an outcome and the process by which actors, ranging from individuals, to families to communities, positively adapt to changing environments (Norris, Stevens, Pfefferbaum, Wyche, \& Pfefferbaum, 2008). Resilience is an important concept across fields as diverse as health planning, engineering and ecology, to economic development and social science (see Rose, 2009). Other definitions understand resilience as a system characteristic. For Holling (1973, p. 14), resilience is a 'measure of the persistence of systems and their ability to absorb change and disturbance and still maintain the same relationships between populations or state variables'. In various parts of the literature, the changes and disturbances to a system are called stressors, which Norris et al. (2008, p. 131) define as 'aversive circumstances that threaten the well-being or functioning of the individual, organization, neighbourhood, community, or society'.

Numerous resilience models show a disaster-impacted community experiencing a period of interruption followed by a progressive return to an equilibrium point (Cutter, 2009; Norris et al., 2008; Zhou, Wang, Wan, \& Jia, 2010). Positive adaptation in the face of a disaster shock incorporates individuals rapidly recovering their wellbeing postdisaster, as well as communities returning to a high, or higher, level of functioning. In achieving a high level of adapted functioning post-disaster, communities are able to develop greater resources to mitigate the impact of future disasters (Berkes \& Ross, 2012; Zhou et al., 2010).

The more recent concept of 'adaptive resilience' is concerned with a 'community's behaviour after the disaster', and how to best support 'community-level activities [that] focus on returning social, economic, and environmental conditions to their previous state' (Kapucu et al., 2013, p. 356). This approach seeks to integrate understandings of resilience, and practices for its promotion, from a number of different fields. Inter-disciplinary perspectives are needed to support 'adaptive resilience', because, as Tierney (2013, p. xiv) notes, it is present in all aspects of the system's way of dealing with hazard events:

"Resilience is a key element in all phases of what is traditionally framed as the 'hazards cycle': mitigation, preparedness, response, and recovery. Prior to disaster, anticipatory resilience consists of activities that enable communities to assess risks, form communities of interest, exercise foresight, and enact mitigation and preparedness measures to manage risks. When disasters strike, responsive resilience makes it possible for social and organisational entities to mobilise resources through emergent interpersonal and inter-organisational networks, to carry out plans, and to improvise and exercise creativity in instances where plans fall short. After disaster, adaptive resilience enables social units to reassess their circumstances, learn from their disaster experiences, and adjust their strategies in light of the 'new normal' ushered in by disaster."
The most comprehensive description of adaptive resilience is provided by Kapucu et al. (2013) (see Figure 1).

The community, or social units, are key to the adaptive resilience framework. In these processes, the 'community participates fully in the recovery process and...has the capacity, skills and knowledge to make its participation meaningful' (Coles \& Buckle, 2004, p. 6). Adaptive governance processes become crucial. Indeed, Shaw (2013, p. 220) notes 'it is increasingly observed and agreed that a sustainable [disaster risk reduction] activity is only possible when there is a strong involvement and commitment from the local institutions'.

\subsection{Issues in Economic Recovery for Regional and Rural Communities}

Extensive research in the United States points to a strong inter-relationship between business recovery and population return post-disaster (Dahlhamer \& Tierney, 1998; Vigdor, 2008; Webb, Tierney, \& Dahlhamer, 2002; Xiao \& Van Zandt, 2012; Zhang, Lindell, \& Prater, 2009). Keeping residents in the local region, and assisting those displaced to return, is critical to business recovery. As Xiao and Van Zandt (2012) identified, the return of businesses to an area acts as a pull factor to the return of local residents. The problem of population displacement and return and its link to business return post-disaster is a variant of the collective action dilemma in which every individual's choice is influenced by the choices of other individuals (Storr \& Haeffele-Balch, 2012). From the perspective of displaced residents, a key factor in the decision to return to a disaster-affected region is the extent to which businesses commit to rebuild and re-open. Research suggests that this relationship is more heavily weighted towards businesses reopening, meaning that business reopening will pull residents back into a disaster affected region (Xiao \& Van Zandt, 2012).

The boom of local economic activity driven by reconstruction is frequently a mirage that masks a longerterm decrease in population and broader business performance issues (see Hayashi, 2012; Vigdor, 2008). Another aspect of the 'reconstruction mirage' faced in recovering communities is the focus on building 'things' to demonstrate commitment and action (Handmer \& Hillman, 2004; Rietveld, Simms, \& Sparrow, 2001). This theory, where economic development is presumed to flow from possessing or building things, is most frequently seen in practice in developing countries (Handmer \& Dovers, 2007; Jacobs, 2000). The focus on building 'things' tends to drive a significant influx of construction workers to the affected region (Vigdor, 2008). The reconstruction boom often distorts measures of a region's economic performance and obscures the long-term challenges faced in achieving sustained economic recovery (Hayashi, 2012; Vigdor, 2008). Hayashi (2012, p. 190) noted this trend in relation to the 1995 Kobe earthquake recovery, observing Kobe's 'economy slid into a long decline, except for the short period during which recon- 


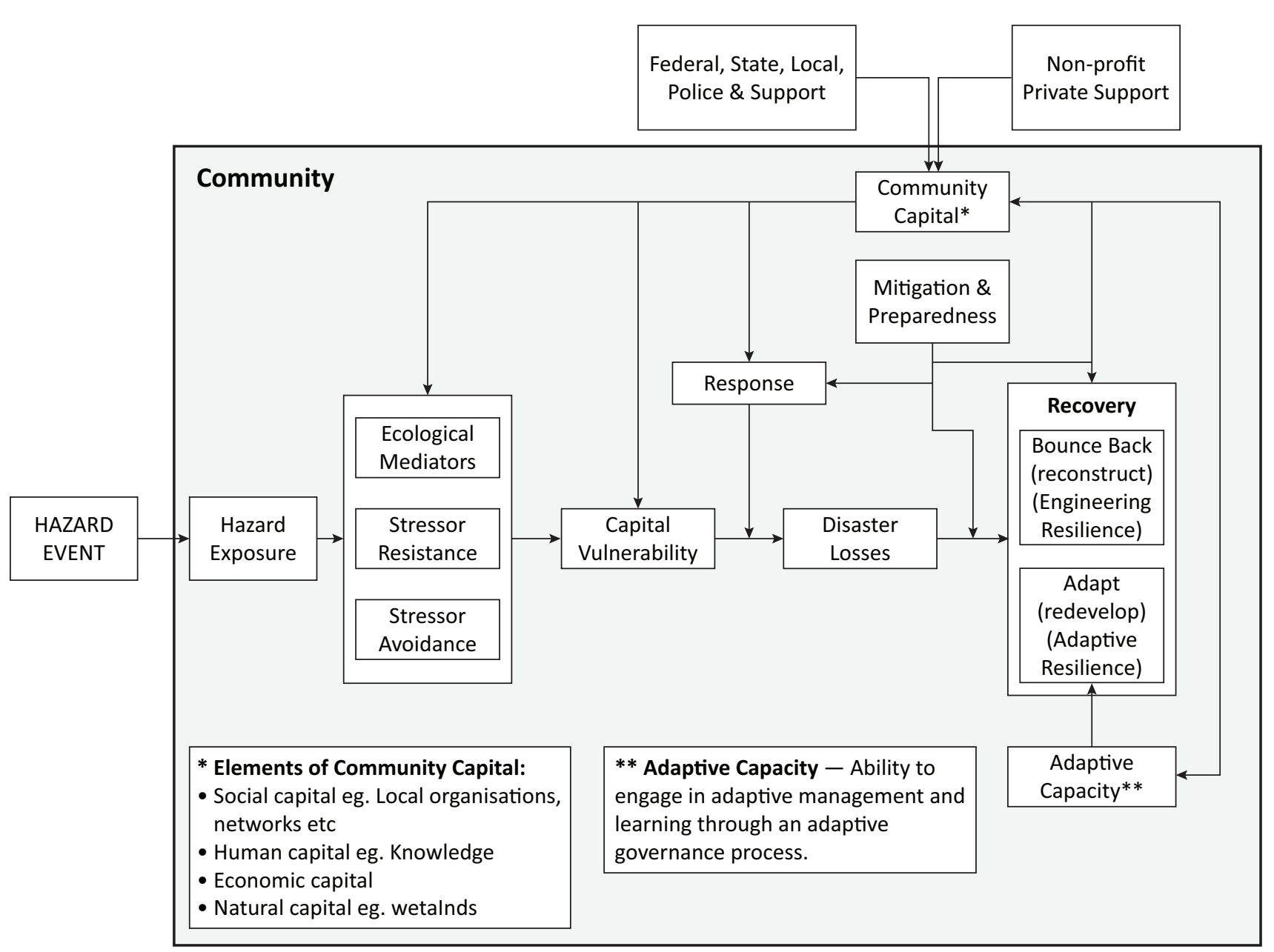

Figure 1. Adaptive resiliency framework. Source: Kapucu et al. (2013, p. 356).

struction spending provided a temporary boost'. New Orleans demonstrated the same pattern, with the construction sector being the only industry sector that did not suffer employment losses after Hurricane Katrina (Vigdor, 2008).

\section{Methodology}

\subsection{Approach}

This research was conducted through a case study approach. We used techniques drawn from the broad toolkit of interpretive policy analysis (Bevir \& Rhodes, 2015; Rhodes, 2011). The method focuses on beliefs and practices; it is concerned with the meaning ascribed to experiences by those involved and seeks to recover their stories. A case study approach is useful when focusing on contemporary events as it enables an up-close interpretation of events through the interviews with people directly involved in those events. How disaster participants construct the meaning of events matters as this construction of a community's shared understanding of a disaster influences its resilience in future events (Alkon, 2004). As Alkon (2004, p. 147) notes 'Stories matter. Place matters. And stories affect place'. The importance of narra- tive and storytelling arises as the construction of meaning is an inherently subjective activity (Alkon, 2004; Riessman, 2008). The case study approach was therefore selected as it allowed researchers to ask explanatory 'how' and 'why' questions (Yin, 2009, p. 4).

The case studies were developed through a structured process of consultation and engagement to identify appropriate interviewees. In each of the case study locations, the research team first met with representatives of the local Council and the Chamber of Commerce to seek support for the project and identify interviewees. The research team also met with members of Community Associations and, in Cardwell, with the CEO of the Girringun Aboriginal Corporation. Researchers visited each of the case study locations to conduct intensive fieldwork, involving semi-structured, qualitative interviews.

\subsection{Case Study Locations}

The case study locations were selected as they had all suffered significant impacts in the various natural disasters. Each was formally declared a State of Disaster under the relevant policy frameworks. Further, due to the extensive damages arising from the events, major recovery 
efforts were undertaken at local and state government levels through specially constituted reconstruction bodies. This formalised approach ensured that extensive documentary evidence of the process of recovery was produced and retained by relevant government agencies.

The article presents the data from three regional centres impacted by natural disasters:

Marysville and Triangle, Victoria, Australia-'Black Saturday' bushfires on 7 February 2009;

Emerald, Queensland, Australia-Southern and central Queensland floods in 2010-2011;

Cardwell, Queensland, Australia-Tropical cyclone Yasi, 2011.

The research team developed socio-economic profiles of each community pre and post disaster (see Table 1). These provided a baseline for comparison, and also highlighted the range of businesses present in each community. We sought interviews with a broadly representative sample of community and business leaders from across the spectrum of industries. In Cardwell, researchers conducted 18 interviews with representatives of industry, business owners, the local Chamber of Commerce, community development association, the Mayor and Council representatives. In Emerald, the research team conducted 18 interviews and a further 22 interviews were conducted in Marysville (total $n=58$ ). Each interview lasted approximately an hour and follow up focus groups were conducted in each location, over a two to three hour period, to discuss the preliminary findings.

\subsection{Data Analysis}

To ensure the case study was rigorous, a comprehensive review of available data and literature was undertaken to provide context to the interview outputs and establish a baseline for analysis (Yin, 2009). In addition to the socio-economic profiles for each case study location noted above, desktop research included reviewing post disaster reports generated by key local groups such as the local Council, Chambers of Commerce and reconstruction authorities. This background research also in- volved requesting the local Councils to complete a comprehensive survey on the impacts of the disaster on the local area and local approaches to recovery.

The qualitative data collected through interviews were analysed using thematic analysis. The interviews were recorded, transcribed and reviewed by the project team. The thematic analysis was undertaken through an emergent inductive approach that sought to identify and draw out themes from the data (Lofland, Snow, Anderson, \& Lofland, 2006). An iterative process of coding was undertaken, seeking first to identify key issues, shared and divergent narratives; and second to review and clarify the emerging analytic themes (Lofland et al., 2006). Different members of the research team reviewed and clarified the thematic analysis as part of an iterative process. Themes were then analysed in light of the existing models of community resilience and recovery (Cutter et al., 2008; Norris et al., 2008). Focus groups were subsequently conducted with key community leaders to reflect on the findings, 'ground truth' the data and identify additional information not elicited during the interviews.

\section{Case Studies of Economic Recovery in Regional Australia}

\subsection{Marysville Case Study-Black Saturday Bushfires, 7 February 2009}

The Marysville Triangle consists of the small communities of Marysville, Buxton, Narbethong and Taggety in the Shire of Murrindindi, about 100 km (62 miles) north-east of Melbourne. The area's economy is based on its natural environment. In addition to tourism, the main industries are agriculture, aquaculture, timber and sawmilling. The Black Saturday bushfires were a series of individual bushfires that burnt across Victoria on Saturday 7 February 2009. The fires resulted in Australia's highest ever loss of life from a bushfire, with 173 fatalities. 414 people were injured, 2,133 homes were destroyed, 78 townships affected, over 4,500 km² (2,796 miles $\left.{ }^{2}\right)$ burned, leaving 7,500 people homeless.

Marysville and the surrounding areas suffered the greatest losses, with 39 people killed (35 Marysville, 4 Narbethong). Of the 452 homes that existed in Marys-

Table 1. Attributes of case study communities.* Source: Australian Bureau of Statistics ([ABS] 2006, 2011).

\begin{tabular}{lllllll}
\hline & \multicolumn{2}{c}{ Marysville } & \multicolumn{2}{c}{ Emerald } & \multicolumn{2}{c}{ Cardwell } \\
\cline { 2 - 7 } & 2006 & 2011 & 2006 & 2011 & 2006 & 2011 \\
\hline Population & 517 & 223 & 10,998 & 12,895 & 1,252 & 1,176 \\
Median Age & 46 & 52 & 28 & 29 & 47 & 52 \\
Median Income per Week & $\$ 974$ & $\$ 880$ & $\$ 1,805$ & $\$ 2,477$ & $\$ 855$ & $\$ 1,004$ \\
Unemployment & $5.5 \%$ & $11.9 \%$ & $1.9 \%$ & $2.4 \%$ & $4.7 \%$ & $5.5 \%$ \\
\hline
\end{tabular}

* Data obtained are Urban Centres and Localities (UCLs) which are an aggregate of Statistical Area 1s (SA1s). They describe populations over 200 people. Urban Centres are areas with a core population greater than 1,000 people. Localities are areas with a population over 200 people and a core urban population less than 1,000 people. Median income is displayed in AUD\$. 
ville prior to the fires, only 34 remained habitable. Fire damage forced the closure of key tourist attractions including Lake Mountain. Almost all the shops and cafés and restaurants were lost. Essential services in Marysville including the police station, the post office, community centre, medical centre, retirement village and the primary school were destroyed.

\subsubsection{Economic Impact}

The total value of tourism to the Marysville economy was estimated at AUD\$33 million (USD\$35 million) per year of which 'visitors' to the area contributed about AUD\$28 million (USD\$30 million) per year (Boston Consulting Group [BCG], 2009, p. 18). With accommodation and tourism the major industry in the Marysville area, only 200 beds of an estimated 1500 remained available.

The large majority of Marysville and Triangle's businesses are 'micro' businesses with revenues of less than AUD\$200k (USD\$214,000) per annum. Their economic recovery has been difficult. For example, the general store did not open for nearly 10 months after the fires. A year on, the Marysville region still did not have a service station operating to supply petrol to local residents.

The immediate damage caused by the fires resulted in extensive displacement of the location population. Of the $90 \%$ of the population who lost their homes, over $50 \%$ have not returned to the region. In addition to the reduction in population since the Black Saturday fires, the age profile has changed dramatically. In 2006, Marysville's age profile showed $36 \%$ aged 55 years and over compared to $24 \%$ for Australia. By 2011 , nearly $47 \%$ were aged 55 years and older. The median age in 2006 of 46 years had increased to 52 in 2011. The data reflects the loss of business and employment opportunities and the need for younger workers to move away in search of employment.

The unemployment rate increased dramatically from $5.5 \%$ in 2006 to $11.9 \%$ in 2011 . Only 90 people indicated in the 2011 Census that they were employed and nearly half of these were working part-time or casually. Median weekly rental increased from \$135 in 2006 to \$350 in 2011 as a result of severe shortages in rental accommodation caused by the Black Saturday fires. In 2006 there were 65 rental accommodation units. There were only nine in 2011.

\subsection{Emerald Case Study-2010-2011 Flooding}

Emerald is the major centre within the Central Highlands Regional Council, approximately 300 km (186 miles) west of the regional city of Rockhampton. Emerald's economy is based on mining and agriculture. Emerald was flooded twice in December 2010. On 3 December, Emerald was isolated when the flooding peaked at 10.95 metres (35.92 feet) at the Vince Lester Bridge. The second flooding peaked on 31 December at 16.05 metres (52.66 feet), surpassing the 1950 record of 15.7 metres ( 49.44 feet). Again Emerald was isolated; this time for 11 days. The town itself was cut in half for seven days.

In Emerald, it was estimated that 1060 residences had water over the floor. 2,500 people were evacuated from their homes with more than 400 staying in one of four evacuation centres at the height of the flooding. It was also estimated that over $100(90 \%)$ buildings in the industrial area and approximately $30 \%$ of commercial offices were impacted by flood waters.

\subsubsection{Economic Impact}

The impacts of the flood were largely felt by small and medium businesses in Emerald Township and the surrounding region. 341 businesses of a total of 386 or $80 \%$ of Emerald's businesses were impacted. In the regional council area, $88 \%$ of businesses affected were in Emerald itself (Central Highlands Regional Council, 2011). According to the Economic Impact report, the total estimated cost of direct damages to businesses (excluding mining) across the Central Highlands as a result of the flooding was AUD\$313.6 million (USD\$336.1 million) (Central Highlands Regional Council, 2011).

$45.5 \%$ of businesses that were forced to close reopened within a week, while a further $19.7 \%$ opened again within two weeks. The average length of time to reopening was 25.2 days.

In the agricultural sector there was major damage to irrigation infrastructure, fencing, plant and equipment and crops and livestock with 35 primary producers in the Emerald service area reporting significant damage. The Economic Impact report assessed that the average cost of repairing infrastructure, equipment and/or replacing stock losses per property as a result of the 2010-2011 flooding was approximately AUD\$306,992 (USD\$329,034).

Access to the mine sites from Emerald was cut for an extended period, and as production was halted mine site operators declared 'Force Majeure' to mitigate claims from customers. However, despite this being a more serious flood than 2008, coal mining representatives who were interviewed agreed that the lessons learnt enabled them to be back in production within eight days, compared with 11-14 days in 2008.

\subsection{Cardwell Case Study-Tropical Cyclone Yasi 2011}

Cardwell is a small coastal community of about 1,200 people, located within the Cassowary Coast Regional Council area of north Queensland. Cardwell's major industries are agriculture (bananas and sugar) and tourism. There is a significant indigenous population in the town. A Category 5 Tropical Cyclone, Yasi made landfall near Mission Beach just north of Cardwell in the early morning of 2 February 2011. Tropical Cyclone Yasi was accompanied by gale force winds with gusts recorded of over $250 \mathrm{~km} / \mathrm{h}$ (155 miles/h). Heavy rain and strong winds were accompanied by a 5 metre (16 foot) storm surge at Cardwell. 
The combined action of the heavy rains, gale force winds and the storm surge resulted in approximately $75 \%$ of the buildings in the town suffering damage. The storm surge was a major contributor to the destruction, particularly at Port Hinchinbrook, on the foreshore and buildings and facilities along and on the eastern side of the main highway.

The town was isolated as fallen trees and debris blocked the road and cut off both sides of the highway, preventing the return of residents for four to five days. Power, telecommunications and water were all compromised.

\subsubsection{Economic Impact}

Following Tropical Cyclone Yasi, Cardwell's estimated resident population declined slightly from 1,252 in 2006 to 1,176 in 2011. Furthermore, its median age increased from 47 years to 52 years between 2006 and 2011. It has a much older age profile than the rest of the country, with $44.4 \%$ being aged 55 years and older compared to the national population age profile of $25.6 \%$ aged 55 years and older. This aging population is also reflected in the industry data with $12.4 \%$ working in the 'health care and social assistance' sector (up from 9.0\% in 2006).

Tropical Cyclone Yasi made these challenges all the more difficult. All businesses in the town were impacted, many for more than 12 months. Some still had not recovered 26 months after the event. The loss of cash flow from sales was exacerbated by the costs of the clean-up, repairs and rebuilding. Limited supplies reduced ability to provide services in the immediate aftermath.

The tourist industry was devastated with consequent 'flow-on' effects to the tourism-related businesses. The regional value of tourism was valued at AUD\$104 million (USD\$111 million) per annum. The Census data shows that in the category of Food and Accommodation the workforce has dropped from $12.3 \%$ in 2006 to $9.3 \%$ in 2011. The post-disaster reconstruction activity changed the employment profile. According to the 2011 Census, $13.5 \%$ of people are working in the Construction sector, up from $8.8 \%$ in 2006.

Local farming and aquaculture suffered immediate and ongoing damage from Tropical Cyclone Yasi, due to extensive crop loss, damage and destruction of mature trees and farm infrastructure. The loss of the season's crop, combined with extensive repair expenses had negative impacts across this sector.

\section{Case Study Findings}

In this section we present empirical findings from a study of economic recovery from natural disasters in regional communities commissioned by the Regional Australia Institute (RAI, 2013). The findings discussed in this section distil key themes that emerged across the case studies.

\subsection{Draw Card Business Provide an Important 'Pull' Factor}

One of the key themes to emerge from all three case studies was that current government recovery policy did not understand or address the complexity of economic recovery. As one Marysville resident succinctly observed, 'The businesses had been forgotten about and not really concentrated on in relation to the recovery'.

Marysville struggled with the circular challenge that without businesses, tourists will not come and people will not invest in businesses without a market to justify the return. Business owners experienced a 'grace' period of support but knew this would be short-lived; 'Yeah look, it's probably been crunch time the last six months because...you can only feed on so many years of sympathy. You've actually got to put up a product'.

The Marysville case study indicated that certain businesses were key 'drawcards' for tourists to the town and they played an important role in spurring economic recovery; 'You need to work out and highlight who are your champion businesses...because you need to support those businesses'. The absence of those drawcard businesses caused significant wider impacts than just the immediate fire damage; 'A lot of the attractions that were up here then (after the fires) didn't bring guests up, tourists up to the area. So it was just the sum of all those had a huge effect'. Marysville residents noted that the artist café and local patisserie shop were attractions that tourists specifically cited as reasons for visiting; 'I remember bed and breakfast people coming and asking meare you staying? Because if you're not staying, there's nothing left here and you know that we need something straight away' (Marysville business owner). Cardwell residents similarly emphasised the 'drawcard' nature of local environmental attractions, 'Because of the damage to Port Hinchinbrook and to the wharf and to the island, with the complete destruction of the resort on the island, the whole tourism industry was severely affected'.

The 'drawcards' in Marysville and Cardwell formed a fundamental aspect of those regions' identity and economic rationale. Their loss had significant impact at a psychological as well as functional level as it came to symbolize the broader disaster impact on the region. In contrast Emerald, which had a diversified economy and key industries largely unaffected by the disaster, was well placed to recover rapidly from the flood's impacts.

The inter-relationship between business reopening and resident decisions to return to a disaster-affected area has been well researched internationally. However, in the absence of a viable market, businesses are less inclined to re-establish themselves after a disaster. Promoting the rapid recovery of housing, along with keeping residents in the local area during the rebuilding process is central to facilitating business recovery. 


\subsection{Population Displacement and the Adaptation Paradox}

One of the critical impacts of disasters on a local economy is the destruction of housing. An immediate flow-on effect is population displacement in the affected region. As the experience of Marysville clearly demonstrates, the longer residents are displaced the less likely they are to return. Of the $90 \%$ of residents who lost their housing, over $50 \%$ have not rebuilt in the region (ABS, 2011; BCG, 2009). It was argued by many remaining residents that had it not been for the temporary village that was established post-disaster, the population exodus would have been greater.

In the aftermath of Tropical Cyclone Yasi, a significant proportion of the local population decided not to return to Cardwell. This decision was influenced by factors such as damage to residences, loss of employment and perceptions about Cardwell's prospects. As one resident noted, 'A lot of the young families left because there was no work'. Similar concerns were expressed in Emerald, with a local real estate agent noting, "because of the publicity of the fact that the whole of Emerald was flooded, therefore nobody wanted to buy in Emerald'.

A critical issue highlighted was the negative impact of this population loss on the community and economy of Cardwell. As the population declined so too did the business opportunities, leading to further job losses and further population loss as job seekers move elsewhere. One Cardwell resident summed up the issues as follows; 'Well there is a decrease in houses. Leads to a decrease in population and a decrease in jobs...leads to a decrease in population. That means a decrease in teachers for the school. Just everything decreases, a total decrease in the town'.

A related dilemma is the role of property investors and 'part time residents' in rural areas. Many 'part-time residents' and investors may deem rebuilding a 'bad bet' after catastrophic natural disasters. The absence of rental housing stock places significant pressure on a local economy, particularly in light of a reconstruction boom. By way of example, 'part-time residents' provided nearly $10 \%$ of Marysville's income. In Cardwell, Emerald and Marysville, the loss of rental housing stock saw rents spike through the reconstruction boom.

Due to the extensive reconstruction required in Cardwell, the reconstruction phase saw a significant influx of construction workers. This was further augmented by the large infrastructure development projects underway in the surrounding region. One Cardwell resident observed that, 'They needed accommodation and with all the rebuilding done and the highway work, there's an influx of workers, that put the rents up very high'. The combination of damaged housing supply and a surge in demand saw rental prices spike. This resulted in marginal populations, such as those who had lost their jobs due to local business interruption, being forced out of the rental market. 'I think we're suffering with the extra workforce because you've got a phenomenon then. They come in, they put their price on, and in that price, they put phenomenal rents. A lot of our local people that's been here all the time are struggling to find somewhere to rent that's affordable.' (Cardwell Resident). Consequently, the reconstruction process served to exacerbate the population displacement problems experienced in Cardwell.

\subsection{The Reconstruction 'Mirage'}

In the aftermath of a major disaster, the reconstruction stage of recovery generally drives a significant influx of construction workers to an affected region. The experience in Cardwell highlighted the change in the regional employment profile during this stage. The reconstruction boom often distorts measures of a region's economic performance and obscures the long-term challenges faced in achieving sustained economic recovery. The reconstruction boom can also have the unintended consequence of furthering population displacement, highlighted by this observation from a Cardwell resident; 'I don't know what Cardwell's going to do when this work's finished. There'll be a lot of empty houses, I think'.

In Marysville and Cardwell, the reconstruction boom drove demand for housing in a market with reduced stock causes rental prices spike, serving to push out local residents in marginal financial circumstances and key workers (see also Yates, Randolph, \& Holloway, 2006). Those most at risk are residents whose employment or employment opportunities have been compromised by interruptions to business operations. The boom of activity driven by reconstruction is frequently a mirage that masks a longer-term decrease in population and broader business performance issues. The data from the case study locations supports this observation; reconstruction activity does not equate to overall economic recovery (see Table 1 above). Residents in Emerald were highly critical of the outsourcing of repair work to non-local businesses, noting:

"It's an absolute slap on the face for the community that has rallied to try and save the community.....It stood out. Everybody saw it. Especially when you've got a community that has got all those people, qualified people, sitting here, who dealt with it [previous flooding] back in 2008, know exactly what has to be done, and has the resources and has the absolute need to have a job, needs an income in this community and they go out of town to get someone else in here."

Although Queensland and Victorian government recovery plans identified long-term outcomes, the experience of residents in affected communities is of a short-term focus on reconstruction. Respondents in the three case study areas expressed deep fears about what would happen after the reconstruction boom ended. Residents in 
disaster affected areas were acutely aware of the reconstruction mirage, directly linked to the masking effect of the reconstruction boom. The dispersion of authority for managing recovery due to the short remit of previous recovery agencies adds to their sense of short-term focus.

Another aspect of the 'reconstruction mirage' faced by Marysville was the Government's commitment to building 'things' to demonstrate action on restoring the town. As one resident noted, 'I think it's seen a bit cynically by a lot of people at the moment because there's all this fantastic infrastructure and there's no-one to use it'.

The highway reconstruction in Cardwell was a similarly hot-button issue for residents. 'The highway was reopened, of course, pretty quickly, but it's not been reconstructed to appropriate standards.' Residents criticised the speed to rebuild without giving serious consideration to 'betterment' of the asset through improvements such as laying a new route and improving the carrying capacity of the road.

There is a difficult balance to strike between government taking action to break the negative consequences of population displacement and investing in 'things' that exacerbate the reconstruction boom yet fail to support long-term community adaptation. The hotly debated new community centre in Marysville embodies this problem; many residents feel it is unnecessary and under-utilised asset. An excessive focus on building 'things' appears to have resulted in over-expenditure on infrastructure that does not serve the community's longterm needs, as it is not integrated with longer-term economic recovery strategies. Early commitment to rebuilding 'things' - under political pressure to be seen to be doing something-also tends to lock-in pre-existing vulnerabilities; opportunities to fundamentally redesign the future of a disaster-affected region may be missed.

\section{Aligning Recovery within a Resilience Framework}

The contracting adaptation spiral (Figure 2), depicts the process by which a business adapts to a shrinking population and, in so doing, exacerbates the problem. Beneath the surface issue of population loss lies a marked change in the demographic composition of the remaining population. As economic opportunities decrease, workingage residents leave the region, meaning that the remaining population becomes older, generally with lower disposable incomes, thereby simultaneously decreasing the economic productivity and increasing the vulnerability of the region. Marysville and Cardwell both exhibited this cycle. Emerald, with a diversified economic base and a strong mining sector, was able to rebound and grow.

The contracting business and population spiral is a logical system response to a major shock and represents adaptation. It exposes the bias inherent in how the term 'adaptation' is deployed in disaster policy. Adaptation is often positively connoted-implying there will be population growth, improvement in GDP and general improvement in the viability of a given region. At a whole-of- system level, by reducing exposure to disasters and the population broadly leaving an unproductive/unsuitable area to seek opportunities elsewhere, the reduction in population size and GDP of the region also represents adaptation. It does not, however, represent 'recovery' through a short-term policy lens.

Researchers in the field of disaster management argue that there has been too much emphasis on response and too little investigation of the economic impacts of disaster and disaster recovery (see, for example, Kapucu \& Liou, 2014, p. 2). As noted above, the potential for more holistic approaches to resilience to be embedded as a key element at all phases of the 'hazards cycle' or PPRR framework (see Tierney, 2013) has been identified as an important direction for future research.

This insight, and calls for more integrated approaches that link disaster management and development, are supported empirically in the Australian context. Our case studies show economic recovery is largely overlooked compared to other recovery streams. In Marysville, for example, governments collectively spent AUD\$135 million (USD\$145 million) on infrastructure and other community recovery activities. In contrast AUD\$2.77 million (USD\$2.23 million) was provided in direct grants to businesses through the NDRRA. This trend was repeated in the other case study communities. Despite the emphasis in official plans and documents on the inter-relationship of all the strands of recovery, there was disproportionate emphasis on the engineering resilience approach of physical reconstruction. Opportunities for redevelopment that might have reflected community values and priorities for future development were not grasped because there had been no pre-event planning to engage the community in contemplating alternative futures-an adaptive resilience approach.

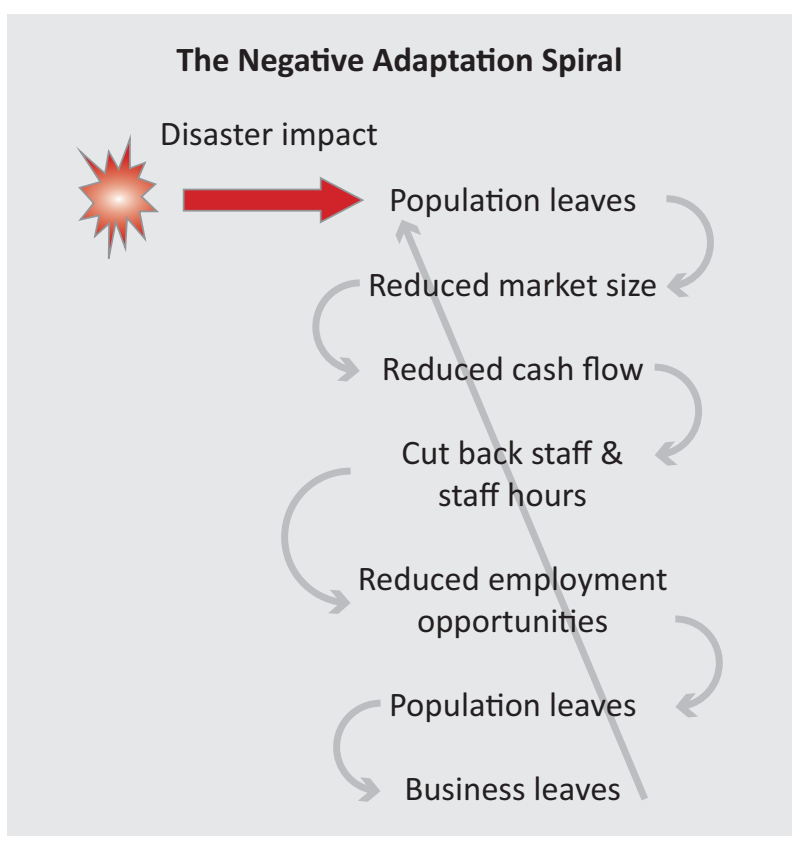

Figure 2. The Contracting Adaptation Spiral. 
Communities with high levels of social capital are better placed to overcome problems of collective decisionmaking and support economic recovery (ChamleeWright \& Storr, 2010; Norris et al., 2008). The interconnectedness of a community with high social capital enables greater information sharing that will therefore provide individuals with more information of other people's intentions from which they can shape their own decision-making (Chamlee-Wright \& Storr, 2010; Storr \& Haeffele-Balch, 2012). Kapucu et al. (2013, p. 357) describe this 'community capital' as embracing the elements of social capital, human capital, economic capital and natural capital. They argue:

"Where a community chooses an adaptive rather than an engineering resilience approach, disaster resilience is considered a function of the community's adaptive capacity. This capacity helps the community engage in adaptive management and continuous learning through an adaptive governance process. In this framework, there is a reciprocal relationship between adaptive capacity and community capital.

Adaptive learning enhances community capital and helps develop local capacity. This in turn influences disaster resilience through mitigation and preparedness that enables a more effective response to and recovery from disasters."

In Australia, the NDRRA's focus on reconstruction, the very limited uptake of the betterment provision, and the lack of integration between the phases of the PPRR framework, means that current arrangements do not support-arguably they inhibit-longer-term adaptation. In the absence of strategic planning that might support adaptive resilience, the primary focus in the wake of a severe disaster event becomes reconstruction and the need to restore critical infrastructure such as power, telecommunications (including internet access, electronic banking and electronic funds transfer), along with rail and road networks. The 'policy window' that the 'focusing event' of a disaster presents for change (Kingdon, 2013) cannot be seized in the absence of broad, clearly articulated and integrated community and economic development plans. This requires greater engagement of local community members in planning processes that canvas the range of risks and hazards that it faces. Kapucu and Liou (2014) highlight institutional memory of previous disaster events as a capacity-building resource that supports self-organisation and thus increased resilience.

Given the 'pull' factor exerted on community recovery decision-making by economic recovery, current policy settings' failure to support economic recovery has significant long-term implications. Research into postdisaster psychological/emotional recovery at the individual and community level has highlighted the importance of economic functions to broad community recov- ery (Norris et al., 2008). Narrow economic bases with high levels of income inequality are correlated to poor individual and community recovery (Adger, 2000; Norris et al., 2008). A community's resilience, and its corresponding ability to adapt post-disaster, is underpinned by its economic base (Norris et al., 2008; Vigdor, 2008).

The distinctions drawn between community recovery and economic recovery, and the seeming lack of focus on economic recovery, miss the vitally importantindeed, the reciprocal link-between the two areas. Community recovery will not occur without economic recovery. In the absence of an adapted and functioning economy, a disaster-impacted region will remain in a state of post-disaster dysfunction (Norris et al., 2008).

\section{Conclusion: Towards Adaptive Resilience}

The increasing frequency and cost of disaster events is among the strongest arguments for policy-makers to embrace an adaptive over an engineering resilience approach that is primarily focused on reconstruction. Disaster events are likely to increase in the future not only because of climate change, but also because of socioeconomic developments such as increased density of settlements, particularly cities, population increase and the increased numbers of settlements in coastal areas (Latham, McCourt, \& Larkin, 2010).

Beyond the financial considerations, there is a strong link between risk reduction strategies and the development of community resilience (Council of Australian Governments, 2011). Australia's NSDR notes that risk reduction strategies include ensuring infrastructure and public assets are able to withstand the range of risks and hazards identified in a community's risk and hazard profile.

Despite good intentions and because of the focus on relief and reconstruction activities, potentially positive outcomes from the recovery experience often are not realized. Recovery needs to be an adaptive process between the experiences of disaster-affected communities, their evolving vision for their future, and their ability to translate this vision into reality. Greater attention to community planning processes in the anticipatory, or prevention and preparedness phases would provide a shared basis for decision-making in the aftermath of a disaster.

A community-led renewal planning process that recognizes the specific local and regional context, along with significant support from government agencies, nongovernment organizations and industry experts, is likely to be more effective than the current recovery process in supporting adaptive resilience, both in terms of outcomes and costs to governments. An integrated national policy and funding framework needs to incentivise proactive investment and planning at the community level for anticipatory resilience, and incorporate development across all other phases of the PPRR framework.

The lesson from major disasters in Australia is that the laudable aspirations of the NSDR need to be matched by actions to achieve its strategic intent. A resilient Aus- 
tralia requires policy and funding frameworks that are consistent with the objective of promoting greater individual and community resilience. Current policy and funding frameworks reinforce the traditional emphasis on response and recovery. We have argued instead for a focus on adaptive resilience. This implies greater investment in mitigation and adaptation strategies-to non-structural (that is human-centred) resilience planning, not the predominant engineering resilience approach. Our Australian case studies lend empirical support to integrated frameworks that seek to build adaptive resiliency.

\section{Acknowledgements}

The authors thank Dr. Tracey Arklay and other Griffith University researchers who contributed to the case studies that formed the basis of the From Disaster to Renewal: The Centrality of Business Recovery to Community Resilience report for the Regional Australia Institute, available at http://www.regionalaustralia.org.au/wp-content /uploads/2013/08/From-Disaster-to-Renewal.pdf.

We acknowledge funding support and input from Jack Archer, CEO of the Regional Australia Institute.

\section{Conflict of Interests}

The authors declare no conflict of interests.

\section{References}

Adger, N. (2000). Social and ecological resilience: Are they related? Progress in Human Geography, 24(3), 347-364.

Alkon, A. H. (2004). Place, stories, and consequences: Heritage narratives and the control of erosion on Lake County, California, vineyards. Organization and Environment, 17(2), 145-169.

Attorney-Generals Department. (2012). Natural disaster relief and recovery arrangements determination, 2012. Retrieved from http://www.disasterassist.gov. au/Documents/Natural-Disaster-Relief-and-Recovery -Arrangements/NDRRA-Determination-2012-v-2.pdf

Australian Bureau of Statistics. (2006). Community profiles. Retrieved from http://www.abs.gov.au/web sitedbs/censushome.nsf/home/communityprofiles? opendocument \&navpos $=230$

Australian Bureau of Statistics. (2011). Community profiles. Retrieved from http://www.abs.gov.au/web sitedbs/censushome.nsf/home/communityprofiles? opendocument\&navpos $=230$

Berkes, F., \& Ross, H. (2012). Community resilience: Toward an integrated approach. Society \& Natural Resources, 26(1), 5-20.

Bevir, M., \& Rhodes, R. A. W. (2015). Interpretive political science: Mapping the field. In M. Bevir \& R. A. W. Rhodes (Eds.), Routledge handbook of interpretive political science (pp. 3-27). Abingdon, Oxon: Routledge.
Boston Consulting Group. (2009). Marysville and triangle economic recovery strategy: Final Recommendations.

Central Highlands Regional Council. (2011). Annual report 2010-2011. Retrieved from http://www.central highlands.qld.gov.au/wp-content/uploads/2015/12/ 2010-11-CHRC-Annual-Report-Final.pdf

Chamlee-Wright, E., \& Storr, V. H. (2010). Expectations of government's response to disaster. Public Choice, 144(1/2), 253-274.

Coles, E., \& Buckle, P. (2004). Developing community resilience as a foundation for effective disaster recovery. Australian Journal of Emergency Management, 19(4), 6-15.

Council of Australian Governments. (2011). National strategy for disaster resilience: Building the resilience of our Nation to disasters. Retrieved from https:// www.coag.gov.au/node/81

Cutter, S. L. (2009). A roadmap to resilience. Environment, $51,3-4$.

Cutter, S. L., Barnes, L., Berry, M., Burton, C., Evans, E., Tate, E., \& Webb, J. (2008). A place-based model for understanding community resilience to natural disasters. Global Environmental Change, 18(4), 598-606.

Dahlhamer, J. M., \& Tierney, K. J. (1998). Rebounding from disruptive events: Business recovery following the Northridge earthquake. Sociological Spectrum, 18(2), 121-141.

Deloitte Access Economics. (2016). The economic cost of the social impact of natural disasters. Retrieved from http://australianbusinessroundtable.com.au/our-pa pers/social-costs-report

Handmer, J., \& Dovers, S. (2007). The handbook of disaster and emergency policies and institutions. London: Earthscan.

Handmer, J., \& Hillman, M. (2004). Economic and financial recovery from disaster. The Australian Journal of Emergency Management, 19, 44-50.

Hayashi, T. (2012). Japan's post-disaster economic reconstruction: From Kobe to Tohoku. Asian Economic Journal, 26(3), 189-210.

Holling, C. S. (1973). Resilience and stability of ecological systems. Annual Review of Ecology and Systematics, 4, 1-23.

Jacobs, J. (2000). The nature of economies. New York, NY: The Modern Library.

Kapucu, N., Hawkins, C. V., \& Rivera, F. I. (2013). Emerging research in disaster resiliency and sustainability: Implications for policy and practice. In N. Kapucu, C. V. Hawkins, \& F. I. Rivera (Eds), Disaster resiliency: Interdisciplinary perspectives (pp. 355-358). New York, London: Routledge.

Kapucu, N., \& Liou, K. T. (2014). Disaster and development. Cham: Springer International.

Kingdon, J. W. (2013). Agendas, alternatives and public policies. Harlow, UK: Pearson.

Latham, C., McCourt, P., \& Larkin, C. (2010). Natural disasters in Australia: Issues of funding and insurance. Paper presented at the 17 th General Insurance 
Seminar, The Institute of Actuaries of Australia, Gold Coast, Australia. Retrieved from http://www. actuaries.asn.au/library/events/GIS/2010/NaturalDi sastersInAustralia-Paper.pdf

Lofland, J., Snow, D., Anderson, L., \& Lofland, L. (2006). Analyzing social settings: A guide to qualitative observation and analysis. Belmont, CA: Thomson Wadsworth.

McGowan, J. (2014). Promoting resilience: A contemporary and integrated policy and funding framework for disaster management. Australian Journal of Emergency Management, 29(2), 8-10.

McGowan J., \& Tiernan, A. (2014). Natural disaster finding arrangements: Submission to the public inquiry by the productivity commission. Retrieved from http://www.pc.gov.au/inquiries/completed/disasterfunding/submissions/submissions-test2/submissioncounter/subdr123-disaster-funding.pdf

Norris, F. H., Stevens, S. P., Pfefferbaum, B., Wyche, K. F., \& Pfefferbaum, R. L. (2008). Community resilience as a metaphor, theory, set of capabilities, and strategy for disaster readiness. American Journal of Community Psychology, 41(1/2), 127-150.

Productivity Commission. (2014). Terms of reference; Natural disaster funding. Retrieved from http://www. pc.gov.au/projects/inquiry/disaster-funding/termsof-reference

Regional Australia Institute. (2013). From disaster to renewal; The centrality of business recovery to community resilience. Retrieved from http://www.regional australia.org.au/wp-content/uploads/2013/08/From -Disaster-to-Renewal.pdf

Rhodes, R. A. W. (2011). Everyday life in British government. Oxford: Oxford University Press.

Riessman, C. K. (2008). Narrative methods for the human sciences. Los Angeles, CA: SAGE Publications.

Rietveld, K., Simms, A., \& Sparrow, J. (2001). The ecology of disaster recovery. World Disasters Report 2001. Retrieved from: http://www.recoveryplatform.org/ assets/publication/9\%20sept/world\%20disaster\%20 report\%20on\%20recovery.pdf

Rose, A. (2009). Economic resilience to disasters: CARRI research report 8 . Prepared for the Community and
Regional Resilience Institute. Retrieved from http:// www.resilientus.org/wp-content/uploads/2013/03/ Research_Report_8_Rose_1258138606.pdf

Shaw, R. (2013). Incorporating resilience of rural communities for proactive risk reduction in Shikoku, Japan. In N. Kapucu, C. V. Hawkins, \& F. I. Rivera (Eds.), Disaster resiliency: Interdisciplinary perspectives (pp. 207226). New York, NY: Routledge.

Storr, V. H., \& Haeffele-Balch, S. (2012). Post-disaster community recovery in heterogeneous, loosely connected communities. Review of Social Economy, 70(3), 295-314.

Tierney, K. (2013). Foreword. In N. Kapucu, C. V. Hawkins, \& F. I. Rivera (Eds.), Disaster resiliency: Interdisciplinary perspectives (pp. xiii-xvi). New York, NY: Routledge.

Vigdor, J. (2008). The economic aftermath of Hurricane Katrina. The Journal of Economic Perspectives, 22(4), 135-154.

Webb. G. R., Tierney, K. J., \& Dahlhamer, J. M. (2002). Predicting long-term business recovery from disaster: $A$ comparison of the Loma Prieta earthquake and Hurricane Andrew. Environmental Hazards, 4(2), 45-58.

Xiao, Y., \& Van Zandt, S. (2012). Building community resiliency: Spatial links between household and business post-disaster return. Urban Studies, 49(11), 2523-2542.

Yates, J., Randolph, B., \& Holloway, D. (2006). Housing affordability, occupation and location in Australian cities and regions: Prepared for the Australian Housing and Urban Research Institute (AHURI). Retrieved from http://www.be.unsw.edu.au/sites/de fault/files/upload/research/centres/cf/publications/ ahuriprojectreports/housingaffordability_fin.pdf

Yin, R. K. (2009). Case study research: Design and methods (4th ed.). Thousand Oaks, CA: Sage Publications.

Zhang, Y., Lindell, M. K., \& Prater, C. S. (2009). Vulnerability of community businesses to environmental disasters. Disasters, 33(1), 38-57.

Zhou, H., Wang, J. A., Wan, J., \& Jia, H. (2010). Resilience to natural hazards: A geographic perspective. Natural Hazards, 53(1), 21-41.

\section{About the Authors}

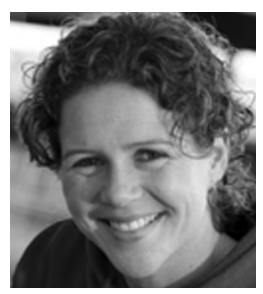

Lex Drennan completed her Master's by research into disaster resilience and recovery at Griffith University. Upon graduating she commenced work with Australia's largest insurer, where she regularly applies her research to help communities and businesses respond to and adapt following disasters. She continues to research in the field of disaster resilience as an Adjunct Research Fellow with Griffith University.

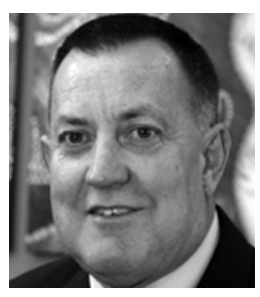

Jim McGowan is an Adjunct Professor with the School of Government and International Relations, Griffith University. Adjunct Professor McGowan has a history of achievement in a variety of challenging leadership roles in the Queensland public sector. He was the Director-General of the Departments of Community Safety, Emergency Services and Justice and Attorney-Generals. Corporate governance, organisational design and reform, performance and service delivery improvement, and the important of relationships were his focus in these leadership roles. 
Professor Anne Tiernan is the Director of the Policy Innovation Hub at Griffith University. A political scientist, with earlier careers in government in the Commonwealth and Queensland, and in teaching and consultancy, Anne is respected for her independent, professional and research-informed analysis and commentary on national politics, public administration and public policy. Her scholarly interests include: Australian politics and governance, policy advice, executive studies, policy capacity, federalism and intergovernmental coordination. She has written extensively on the political-administrative interface, caretaker conventions, governmental transitions and the work of policy advising. 